\title{
Article
}

\section{High-Grade B-Cell Lymphoma Not Otherwise Specified (HGBL, NOS) in the Maxillary Sinus Mimicking Periapical Inflammation: Case Report and Review of the Literature}

\author{
Andrea Brody ${ }^{1, *,+}{ }^{(}$, Csaba Dobo-Nagy ${ }^{1}$ C, Karoly Mensch ${ }^{1}$, Zsuzsanna Oltyan ${ }^{1}$, Judit Csomor ${ }^{2}$, \\ Mariana Pacurar ${ }^{3}$ and Adrienn Dobai ${ }^{1}$ \\ 1 Department of Oral Diagnostics, Faculty of Dentistry, Semmelweis University, Szentkirályi u. 47, \\ 1088 Budapest, Hungary; dobo-nagy.csaba@dent.semmelweis-univ.hu (C.D.-N.); \\ menschkaroly@gmail.com (K.M.); hompothzsuzsanna@gmail.com (Z.O.); adrienn.dobai@gmail.com (A.D.) \\ 2 Department of Pathology and Cancer Research, Semmelweis University, Üllői út 26, 1085 Budapest, Hungary; \\ jmj.csomor@gmail.com \\ 3 Faculty of Dental Medicine, Universitatea Mediciná, Farmacie, Stinte si Technologie, \\ 540088 Targu Mures, Romania; mariana.pacurar@umfst.ro \\ * Correspondence: brody.andrea@gmail.com; Tel.: +36-30-9193-680 \\ † The works should be attributed to Semmelweis University, 1085 Üllói út 26, 1085 Budapest, Hungary.
}

Citation: Brody, A.; Dobo-Nagy, C. Mensch, K.; Oltyan, Z.; Csomor, J.; Pacurar, M.; Dobai, A. High-Grade B-Cell Lymphoma Not Otherwise Specified (HGBL, NOS) in the Maxillary Sinus Mimicking Periapical Inflammation: Case Report and Review of the Literature. Appl. Sci. 2021, 11, 8803. https://doi.org/ 10.3390/app11198803

Academic Editors: Paola Gandini and Andrea Scribante

Received: 24 August 2021

Accepted: 18 September 2021

Published: 22 September 2021

Publisher's Note: MDPI stays neutral with regard to jurisdictional claims in published maps and institutional affiliations.

Copyright: (C) 2021 by the authors. Licensee MDPI, Basel, Switzerland. This article is an open access article distributed under the terms and conditions of the Creative Commons Attribution (CC BY) license (https:/ / creativecommons.org/licenses/by/ $4.0 /)$.
Abstract: High-grade B-cell lymphoma not otherwise specified is listed as a new group in the WHO 2017 statement as a subtype of aggressive, mature B-cell lymphomas with a poor prognosis. To our knowledge, no description of this genetic type of maxillary lymphoma has appeared in the literature until now; thus, our case provides valuable data on its symptoms, clinical behavior, response to treatment and survival rate. The present report describes the early diagnosis and treatment of an extremely rare histological subtype of B-cell lymphoma, a case of high-grade B-cell lymphoma not otherwise specified, localized in the maxillary sinus and mimicking signs and symptoms of periapical inflammation. After chemotherapy, the presented patient showed complete remission without relapse and systemic spread. As far as we know, this is the first reported case of this rare type of lymphoma associated with the maxillary sinus. Considering that high-grade B-cell lymphomas are aggressive tumors with rapid growth and poor prognosis, which are often misdiagnosed in the early stages as inflammatory disease, it is relevant to highlight the importance of a detailed evaluation of clinical signs and radiological findings during diagnosis, especially if they contradict each other.

Keywords: HGBL; NOS; maxillary sinus; non-Hodgkin B-cell lymphoma; mimicking periapical inflammation; rarely diagnosed

\section{Introduction}

Non-Hodgkin lymphoma (NHL) represent less than $1 \%$ of all malignant tumors in the head and neck region, although they represent the second most common localization in the gastrointestinal tract [1,2]. In most cases, NHL involve the cervical, axillary and inguinal lymph nodes, but approximately $40 \%$ present extra-nodal location, such as in the gastrointestinal tract and head and neck region, central nervous system and cutis [3-5]. In the head and neck region, the most commonly affected areas are the Waldeyer's ring, the posterior tongue, the nasopharynx, the hard palate, the paranasal sinuses, the thyroid gland and the parotid gland. Diagnosis of NHLs in the maxillary sinus is rare $[4,6,7]$. Wolvius et al. examined 34 cases with primary oral NHLs and described involvement primarily of the maxillary mucosa or maxillary bone structures, whereas maxillary sinuses were shown to be only secondarily affected [8]. Considering the prevalence of NHLs of the paranasal sinuses, their main location is the maxillary sinus, followed by the ethmoid, sphenoid and frontal sinuses [9]. 
Besides its location, genetic origin is the most important prognostic factor of B-cell NHL. Based on the WHO (2017) statement, high-grade B-cell lymphoma (HGBL) has been defined within mature B-cell NHL as a separate group distinct from diffuse large B-cell lymphoma (DLBCL), which is predominant in the head and neck [10], other large B-cell lymphomas and Burkitt lymphoma (BL) [11]. Despite differences of the immunological and pathological characteristics of HGBL and BL or DLBCL, NOS, the morphology is similar $[9,12]$. Therefore, the WHO 2008 statement defined these groups as B-cell lymphomas, unclassifiable, with features intermediate between DLBCL and BL, but this definition is no longer recommended [13]. HGBL is a special class of aggressive mature lymphomas, and it includes two subtypes: (1) double or triple hit HGBL lymphomas, and (2) high-grade B-cell lymphoma not otherwise specified (HGBL, NOS), or double-expressor lymphomas (DEL) [11,14-16]. If MYC and BCL-2 and/or BCL-6 rearrangements are present, they are categorized as HGBL with MYC and BCL-2 and/or BCL-6 rearrangements. In exceedingly rare cases the lymphoma is not attributed to BL, DLBCL or any other form of HGBL, with MYC translocation and BCL-2 or BCL-6 amplification. These lymphomas are not double hit, but double-expressor lymphomas, with a poor prognosis $[11,12,17]$ (Figure 1). The MYC gene encodes an oncogenic protein, which leads to a proliferation of immature B cells. The protein encoded by BCL-2 inhibits apoptosis. The expression of BCL-6, a transcriptional repressor, helps in the development of lymphoma $[15,18]$.

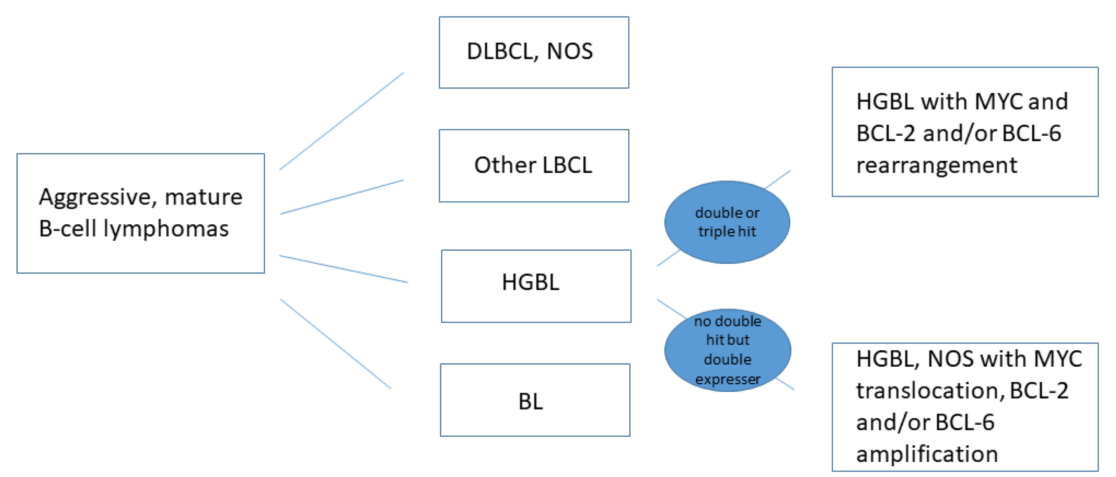

Figure 1. New WHO classification of HGB lymphomas [11].

Both subtypes, especially the HGBL, NOS, are rarely diagnosed [12,19], and while other mature B-cell lymphomas such as DLBCL have an average of 70\% complete remission and a high average 5-year survival rate of $60 \%[1,20]$, the prognosis of HGBL, NOS is poor [14,21-23]. Despite the very rapid spread, there are few clinical signs of NHL-affected jaws, and these signs may mimic benign inflammatory diseases, thus leading to a delay of the correct diagnosis [24,25].

Limited data are available on the clinicopathological features of HGBL, NOS lymphoma, as it is often included in reports with other types such as DLBCL, NOS [22]. The present article reports a rare case of HGBL NOS involving the maxillary sinus and maxillary bone in an adult male with atypical clinical presentation, mimicking a periapical inflammation. The report provides relevant information about the clinical features and therapeutic efficacy of the HGBL, NOS in the maxillary sinus and the difficulty of distinguishing the disease from a periapical inflammation.

\subsection{Case Report}

A 52-year-old male patient visited a dental outpatient clinic because of clinical signs and symptoms of periapical inflammation including pain and swelling of the left side of the face, pain for vertical percussion on teeth 24 and 25 and negative sensibility tests of both teeth, which presented extensive MOD composite fillings. Stomato-oncological screening was carried out, and no signs of premalignant lesion, malignancy or palpable lymph nodes were found [26]. Except for smoking, no relevant issues were registered in the patient's medical history. A diagnosis of acute apical periodontitis was made for both teeth, and 
the trepanation of both premolars was performed by the dentist. Due to difficulties in the sclerotic root canal preparation and the lack of any clinical improvement, the patient was referred to the Department of Oral Diagnostics at Semmelweis University, where he underwent root canal treatment. Despite the successful treatment, two weeks after treatment completion, clinical signs and symptoms, including aching pain and numbness in the upper left facial region, increased. Clinical examination of the alveolar process in the region of the upper left molars revealed a painless swelling on the hard palate, $2 \mathrm{~cm}$ in diameter. The swollen area was tough, painless and covered with intact mucosa (Figure 2). Additionally, the patient's oral hygiene was poor and signs of chronic periodontitis were detected.

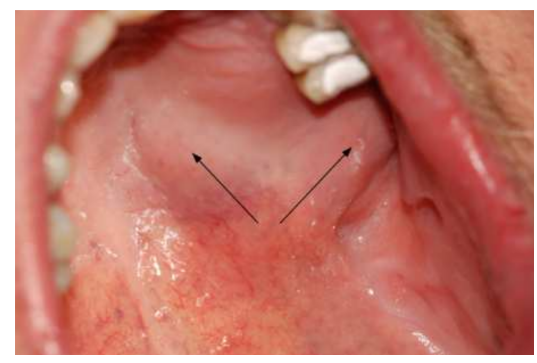

Figure 2. Painless swelling of the hard palate and the alveolar process.

An incisional biopsy was performed from the palatal swollen area. Following local anesthesia, in order to perform a histological diagnosis, three elliptical incisions were taken from the representative areas of the lesion, including its periphery. To close the wound, single interrupted sutures were used. The samples were placed in a $4 \%$ formaldehyde solution in $0.1 \mathrm{M}$ phosphate buffer saline (PBS), $\mathrm{pH} 7.3$, stored at $4{ }^{\circ} \mathrm{C}$. The preliminary diagnosis was a tumor of the left maxilla.

Because of the swollen area's location, an additional periapical X-ray of teeth 24 and 25 was performed. No signs of periapical lesions were seen, but oval formed bone destruction was detected in the imaged part of the upper left molar region (Figure 3).

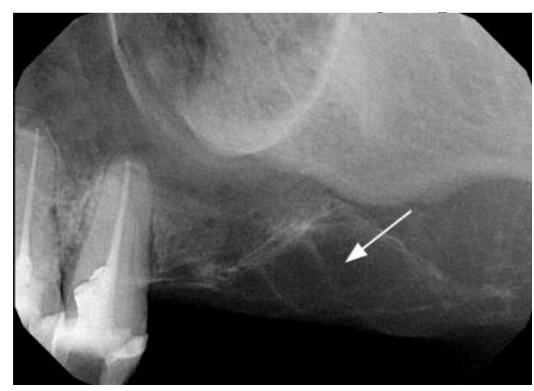

Figure 3. Periapical X-ray of the upper left molar region with the lesion of the processus alveolaris in the molar region.

On the follow-up orthopantomography (OP), extensive bone destruction was noted in the upper left molar alveolar bone and around the left maxillary tuberosity. Opacity of both maxillary sinuses was detected, predominantly on the left side (Figure 4). Based on the X-ray images, ameloblastoma [27], cemento-osseous dysplasia [28] or malignant lesions were suspected, and additional magnetic resonance imaging (MRI) was performed. On these MRI scans, the suspect lesion completely filled the left maxillary sinus and showed medium signal intensity on T2 and T1 sequences and inhomogeneous contrast enhancement on the post-contrast images. On the diffusion-weighted, whole-body imaging with background body signal suppression (DWIBS) sequences, the mass showed diffusion restriction with low apparent diffusion coefficient (ADC) values on the ADC map. The lesion inflated the maxillary sinus with a slight dislocation of the walls and markedly eroded the maxillary alveolar bone and the posterior wall of the maxillary sinus. The mass spread to the ostium of the maxillary sinus and filled the infundibulum. The lesion involved part of the left side of the palate and infiltrated the lateral pterygoid muscle, 
the buccinator muscle and parts of the medial pterygoid muscle. The MRI imaging was characteristic for malignant lymphoma, as Kawaguchi et al. described [29]. In the right maxillary sinus, the ethmoid cell system and the sphenoidal sinus, concentric mucosa thickening was visible. No pathologic lymph node was visualized in the head and neck region. (Figure 5.)

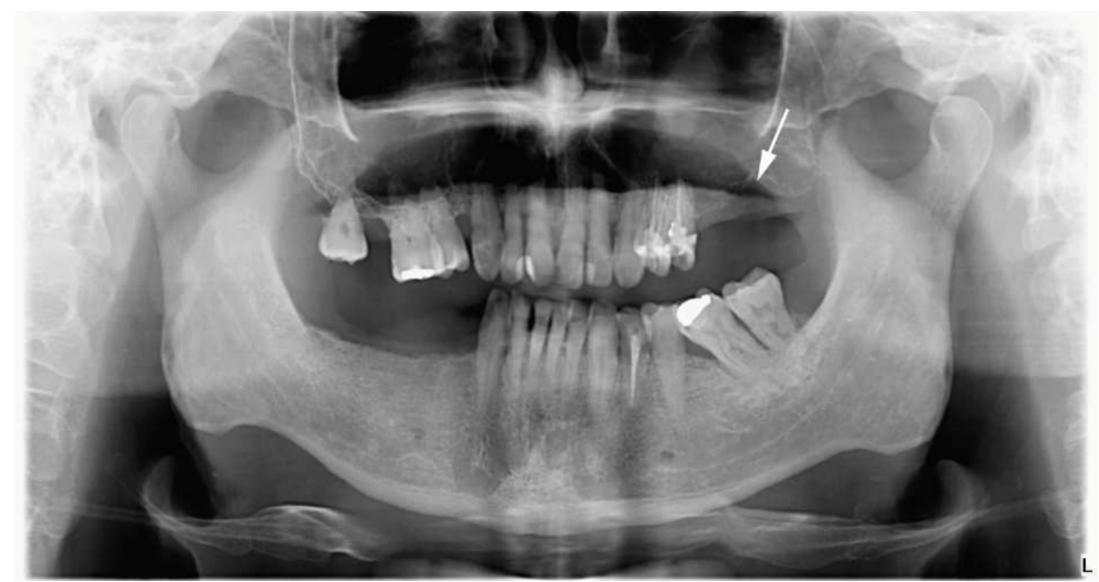

Figure 4. Orthopantomography with the maxillary lesion on the left molar region.

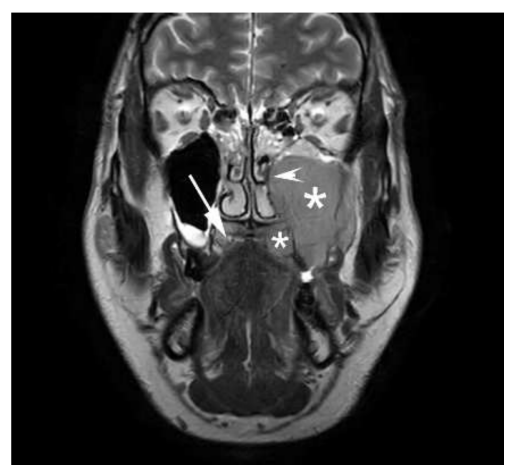

Figure 5. Coronal T2 weighted magnetic resonance imaging of the lesion involving hard palate and the left maxillary sinus. The * sign indicates the tumor mass. White arrow shows the intact part of hard palate on the right side. White arrowhead marks the dislocation of the medial wall of the left maxillary sinus.

The patient was referred to the Department of Internal Medicine of Semmelweis University.

\subsection{Histology, Immune-Histochemistry, Fluorescence In Situ Hybridization (FISH)}

Microscopically, a diffuse infiltrate of medium-sized tumor cells was found in the biopsy sample. The cells were monomorphic, approximately $20 \mu \mathrm{m}$ in size and had scanty, basophilic cytoplasm. The nuclei were ovoid, with a loose chromatin structure in most of the cells. The immunophenotype was CD45+, CD20+, CD10+, BCL6+, BCL2+, CD3-, CD5-, CD34-, TdT-, and C-Myc expression was detected in nearly $100 \%$ of the tumor cells. The Ki-67 proliferation index was around $40 \%$. Using FISH, a rearrangement affecting the MYC (8q24) gene was detected, while BCL-2 (18q21) and BCL-6 (3q27) genes were intact. By histology, HGBL, NOS was diagnosed, with a germinal center phenotype and MYC gene rearrangement, according to the current criteria [17] (Figure 6).

\subsection{Treatment}

The patient received six series of 21-day R-CHOP immuno-chemotherapeutic treatments because of the histologically verified I/A-E grade (extra nodal appearance in only one region without general symptoms) HGBL NOS, complemented with intrathecal methotrexate due to the close proximity to the central nervous system (R-CHOP therapy: $800 \mathrm{mg}$ of 
Truxima iv. on the first day, $1600 \mathrm{mg}$ of Cytoxan, $2 \mathrm{mg}$ of Vincristin, $110 \mathrm{mg}$ of Doxorubicin i.v., $100 \mathrm{mg}$ of Medrol on the second to fifth days, $15 \mathrm{mg}$ of methotrexate intrathecal on the first day). He was also given Aciclovir: $400 \mathrm{mg}$ /day. No serious side effects were noted during the treatment. The interim PET-CT (positron emission tomography and computed tomography) showed complete metabolic remission, followed by completion of the treatment with two further series of immunotherapies with Rituximab (800 mg of Truxima i.v., $125 \mathrm{mg}$ of Solu-Medrol iv).

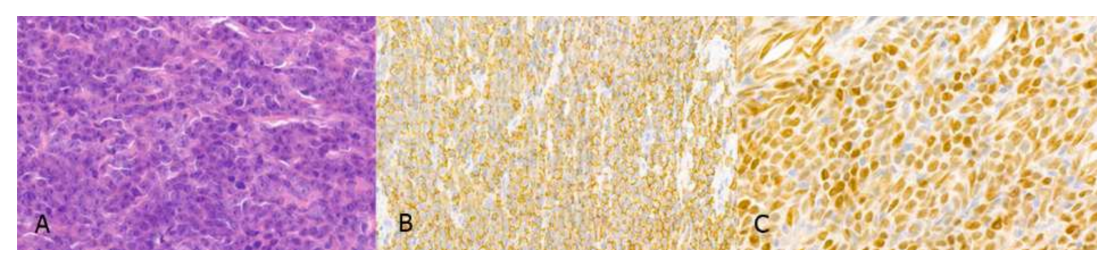

Figure 6. Histopathologic features of the tumor: (A) The maxillary tumor is composed of medium sized tumor cells with ovoid nuclei containing prominent central or multiple smaller nucleoli (H\&E, $63 \times$ ). (B) The tumor cells are homogenously positive with CD20 antibody (CD20/peroxidase, $40 \times$ ). (C) $100 \%$ nuclear C-MYC expression is detected by immunohistochemistry $(63 \times)$.

By the time of the follow-up MRI, the tumor showed total regression in the region of the maxillary sinus. In both maxillary sinuses, concentric mucosal thickening was observed. The patient was monitored for two years without any relapse (Figure 7).

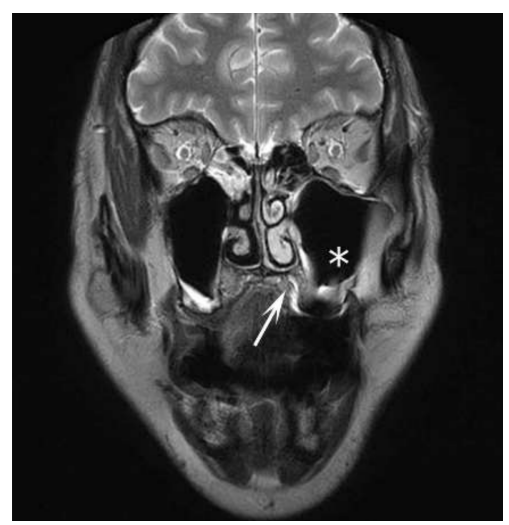

Figure 7. Follow-up MRI at 6-months: coronal T2 weighted image shows total regression. The * sign indicates the pneumatized left maxillary sinus. The white arrowhead marks the left side of the hard palate without tumor mass.

\subsection{Discussion}

The presence of extra nodal lymphomas of the jawbones is exceptional [10,30]. Since very little data are available on the pathogenesis and clinical behaviour of HGBL, NOS lymphomas are referred to as "grey-zone" lymphomas, and there is no consensus on their standard therapy [23]. There are few reports of NHL in the maxillary sinus [9,31,32], but, to our knowledge, the present case represents the first description of HGBL, NOS located in the maxillary sinus.

The origin of NHL of the jaw is unclear, although several authors suggested a possible role of chronic inflammation, supported by the fact that these malignomas are often first diagnosed as periapical inflammation or osteomyelitis [9,32-34]. In the present case, a question also arose as to whether the trepanation of the 24 and 25 teeth was based on a reliable diagnosis.

The most frequent symptoms of NHL arising within the maxillary sinus are pain, swelling, nasal obstruction, paresthesia and numbness $[25,30]$. The patient had few or no typical complaints, suggesting the presence of periapical inflammation and maxillary sinusitis localized to the left upper premolar region; therefore, a definitive diagnosis was 
hardly determinable. OP and periapical images showed alveolar lesions and bone destruction, as well as well circumscribed opacity in the maxillary sinus. Based on these findings, the possible co-existence of sinusitis and alveolar bone lesions-primarily ameloblastomaas well as some malignancy has to be taken into account. As a result of the MRI examination, the relationship between the X-ray lesions and the extent of a malignant process became obvious. We performed the FISH test according to current recommendations [22], and it revealed the diagnosis was double-expressor HGB NOS non-Hodgkin lymphoma, which is usually characterized by rapid progression and poor therapeutic response.

Analyzing three reports from the literature on maxillary NHL, Gill et al. reported a case of high-grade non-Hodgkin lymphoma. The extent of the tumor mass was similar to our case, but the type of lymphoma was only defined as B-cell high-grade non-Hodgkin's lymphoma. The significance of the case is that the initial symptoms mimicked the appearance of odontogenic inflammation as in our patient, for which tooth extraction was performed [25]. In the second case, described by Doumas et al., a rapid growth was observed, and the patient's temporal swelling increased rapidly within 10 days after onset, with the development of blurred and double vision in the left eye during the 2 weeks of antibiotic therapy, and exophthalmia and facial paresis within the following 15 days [9]. In MacDonald's case, the tumor extension increased by more than $30 \%$ in just one week [4]. A comparison of these cases with the present one was difficult, since the first case was diagnosed as DLBCL by immunohistochemical analysis, whereas MacDonald's case study did not include data about the histological subtype of NHL. However, similar to these reports, the patient's symptoms worsened rapidly, and pain and numbness increased significantly within 1 week, highlighting the importance of a careful and prompt diagnosis within a short time period and the rapid start of chemotherapy.

HGBL NOS lymphoma is a rapidly growing, infiltrating, poor prognostic tumor, rarely diagnosed in the maxilla. In the present case, oral lesions were discrete and unspecific, with the tumor infiltrating the maxillary sinus and the masticatory muscles aggressively. Unexpectedly, the tumor responded quickly to chemotherapy, resulting in complete remission.

In conclusion, the present report underlines the importance of a meticulous diagnosis of routine dental X-ray examinations, with an accurate investigation of the paranasal sinuses and the bony structures of the jaw.

Author Contributions: The corresponding author A.B. examined the patient, reviewed the literature and prepared the manuscript. A.D. carried out and evaluated the MRI and contributed in the writing and revision of the manuscript. C.D.-N. supervised the patient treatment and the preparation of the manuscript, analyzed and evaluated the MRI radiographs. K.M. carried out the root canal treatment and contributed to the acquisition of data and in the revision of the manuscript. J.C. prepared and evaluated the pathological samples and contributed in the revision of the manuscript. All authors analyzed the results, read and approved the final version of the manuscript, and agreed to the submission. All authors have read and agreed to the published version of the manuscript.

Funding: This research received no external funding.

Institutional Review Board Statement: Not applicable.

Informed Consent Statement: Not applicable.

Data Availability Statement: All data generated or analyzed during this case study are included in this published article.

Acknowledgments: We thank Péter Farkas and his team from the 3rd Department of Internal Medicine of Semmelweis University for the successful treatment and follow up the patient.

Conflicts of Interest: The authors declare that they have no competing interest. 


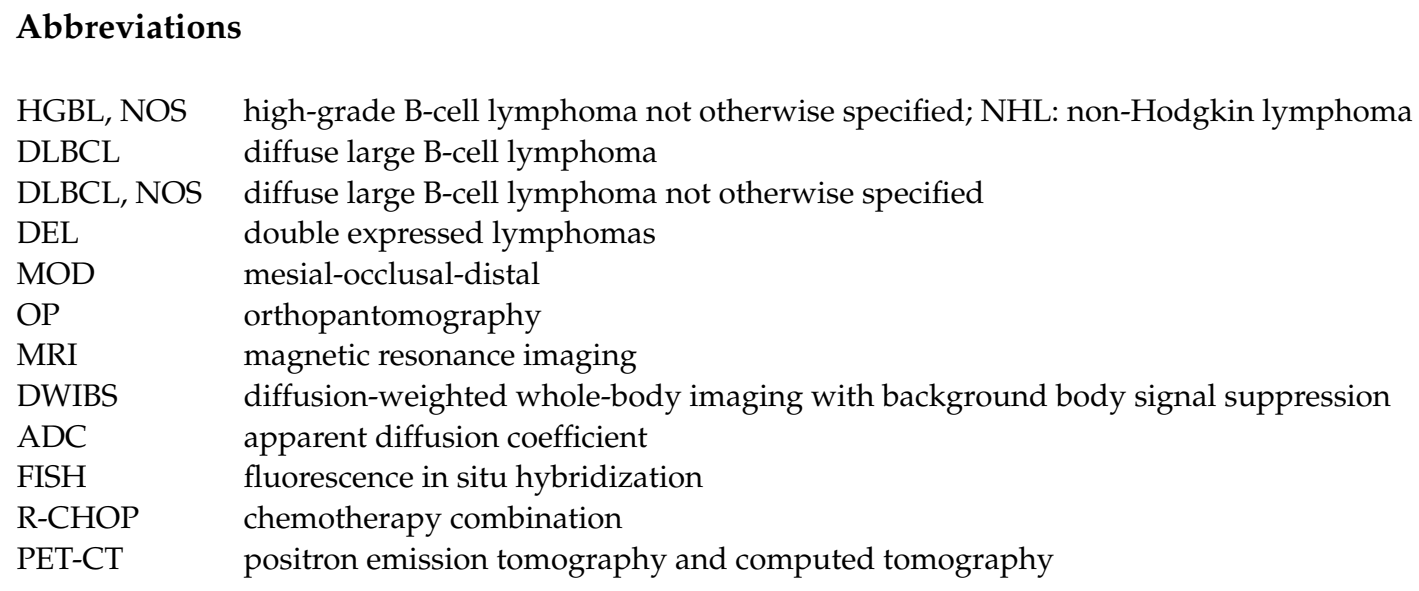

\section{References}

1. Rodrigues-Fernandes, C.I.; de Souza, L.L.; Santos-Costa, S.F.D.; Pontes, H.A.R.; de Almeida, O.P.; Vargas, P.A.; Henao, J.R.; Rahimi, S.; Brennan, P.A.; Fonseca, F.P. Clinicopathological analysis of oral diffuse large B-cell lymphoma, NOS: A systematic review. J. Oral Pathol. Med. 2019, 48, 185-191. [CrossRef] [PubMed]

2. Walter, C.; Ziebart, T.; Sagheb, K.; Rahimi-Nedjat, R.K.; Manz, A.; Hess, G. Malignant lymphomas in the head and neck region-A retrospective, single-center study over 41 years. Int. J. Med. Sci. 2015, 12, 141-145. [CrossRef] [PubMed]

3. Das, J.; Ray, S.; Sen, S.; Chandy, M. Extranodal involvement in lymphoma-A Pictorial Essay and Retrospective Analysis of 281 PET/CT studies. Asia Ocean. J. Nucl. Med. Biol. 2014, 2, 42-56. [PubMed]

4. MacDonald, D.; Li, T.; Leung, S.F.; Curtin, J.; Yeung, A.; Martin, M.A. Extranodal lymphoma arising within the maxillary alveolus: A case report. Oral Surg. Oral Med. Oral Pathol. Oral Radiol. 2017, 124, e233-e238. [CrossRef]

5. Silva, T.; Ferreira, C.; Leite, G.; Pontes, J.; Antunes, H. Oral manifestations of lymphoma: A systematic review. Ecancermedicalscience 2016, 10, 665. [CrossRef]

6. Kamulegeya, A.; Kalyanyama, B.M. Oral maxillofacial neoplasms in an East African population a 10 year retrospective study of 1863 cases using histopathological reports. BMC Oral Health 2008, 8, 19. [CrossRef]

7. Nagafuji, H.; Yokoi, H.; Ohara, A.; Fujiwara, M.; Takayama, N.; Saito, K. Primary diffuse large B-cell lymphoma of the frontal sinus: A case report and literature review. Radiol. Case Rep. 2018, 13, 635-639. [CrossRef] [PubMed]

8. Wolvius, E.B.; van der Valk, P.; van der Wal, J.E.; van Diest, P.J.; Huijgens, P.C.; van der Waal, I.; Snow, G.B. Primary extranodal non-Hodgkin lymphoma of the oral cavity. An analysis of 34 cases. Eur. J. Cancer B Oral Oncol. 1994, 30, 121-125. [CrossRef]

9. Doumas, S.; Sakkas, L.; Panayiotidis, P.; Wozniak, G.; Vlychou, M.; Vassilopoulos, G. Favorable outcome in non-Hodgkin lymphoma of the maxillary sinus treated with R-CHOP. Arch. Med. Sci. 2014, 10, 406-409. [CrossRef]

10. Iguchi, H.; Wada, T.; Matsushita, N.; Oishi, M.; Yamane, H. Anatomic distribution of hematolymphoid malignancies in the head and neck: 7 years of experience with 122 patients in a single institution. Acta Oto-Laryngol. 2012, 132, 1224-1231. [CrossRef] [PubMed]

11. Steven, H.; Swerdlow, E.C.; Harris, N.L.; Jaffe, E.S.; Pileri, S.A.; Stein, J.T.H.; Arber, D.A.; Hasserjian, R.P.; Michelle, M.; Beau, A.O.L.; et al. WHO Classification of Tumours of Haematopoietic and Lymphoid Tissues, 4th ed.; IARC: Lyon, France, 2017.

12. Grimm, K.E.; O'Malley, D.P. Aggressive B cell lymphomas in the 2017 revised WHO classification of tumors of hematopoietic and lymphoid tissues. Ann. Diagn. Pathol. 2019, 38, 6-10. [CrossRef] [PubMed]

13. Jaffe, E.S.; Pittaluga, S. Aggressive B-cell lymphomas: A review of new and old entities in the WHO classification. Hematol. Am. Soc. Hematol. Educ. Program. 2011, 2011, 506-514. [CrossRef]

14. Ahn, J.Y.; Seo, Y.H.; Park, P.W.; Kim, K.H.; Park, M.J.; Jeong, J.H.; Park, S.H.; Song, Y.H. A case of B-cell lymphoma, unclassifiable, with features intermediate between diffuse large B-cell lymphoma and Burkitt lymphoma in a Korean child. Ann. Lab. Med. 2012, 32, 162-166. [CrossRef]

15. Bemis, T.; Ioanitescu, J.; Mackovick, L.; Hammad, A.; Rubin, J. A Case of Double Expresser Diffuse Large B Cell Lymphoma Treated with R-CODOX-M/R-IVAC. Case Rep. Oncol. 2019, 12, 595-602. [CrossRef] [PubMed]

16. Rosenthal, A.; Younes, A. High grade B-cell lymphoma with rearrangements of MYC and BCL2 and/or BCL6: Double hit and triple hit lymphomas and double expressing lymphoma. Blood Rev. 2017, 31, 37-42. [CrossRef] [PubMed]

17. Szumera-Cieckiewicz, A.; Rymkiewicz, G.; Grygalewicz, B.; Jesionek-Kupnicka, D.; Gruchala, A.; Ziarkiewicz-Wroblewska, B.; Galazka, K.; Reszec, J.; Borg, K.; Prochorec-Sobieszek, M. Comprehensive histopathological diagnostics of aggressive B-cell lymphomas based on the updated criteria of the World Health Organisation's 2017 classification. Pol. J. Pathol. 2018, 69, 1-19. [CrossRef] [PubMed]

18. Kikuchi, K.; Inoue, H.; Miyazaki, Y.; Ide, F.; Matsuki, E.; Shigematu, H.; Okamoto, S.; Sakashita, H.; Kusama, K. Adult sporadic burkitt lymphoma of the oral cavity: A case report and literature review. J. Oral Maxillofac. Surg. 2012, 70, 2936-2943. [CrossRef] [PubMed] 
19. Jesionek-Kupnicka, D.; Braun, M.; Robak, T.; Kuncman, W.; Kordek, R. A large single-institution retrospective analysis of aggressive B-cell lymphomas according to the 2016/2017 WHO classification. Adv. Clin. Exp. Med. 2019, 28, 1359-1365. [CrossRef]

20. Oprea, C.; Cainap, C.; Azoulay, R.; Assaf, E.; Jabbour, E.; Koscielny, S.; Lapusan, S.; Vanel, D.; Bosq, J.; Ribrag, V. Primary diffuse large B-cell non-Hodgkin lymphoma of the paranasal sinuses: A report of 14 cases. Br. J. Haematol. 2005, 131, 468-471. [CrossRef]

21. Bischin, A.M.; Dorer, R.; Aboulafia, D.M. Transformation of Follicular Lymphoma to a High-Grade B-Cell Lymphoma with MYC and BCL2 Translocations and Overlapping Features of Burkitt Lymphoma and Acute Lymphoblastic Leukemia: A Case Report and Literature Review. Clin. Med. Insights Blood Disord. 2017, 10, 5421. [CrossRef]

22. Chen, B.-J.; Fend, F.; Campo, E.; Quintanilla-Martinez, L. Aggressive B-cell lymphomas-From morphology to molecular pathogenesis. Ann. Lymphoma. 2019, 3. Available online: https://aol.amegroups.com/article/view/4949 (accessed on 22 September 2021).

23. Li, J.; Liu, X.; Yao, Z.; Zhang, M. High-Grade B-Cell Lymphomas, Not Otherwise Specified: A Study of 41 Cases. Cancer Manag. Res. 2020, 12, 1903-1912. [CrossRef]

24. de Castro, M.S.; Ribeiro, C.M.; de Carli, M.L.; Pereira, A.A.C.; Sperandio, F.F.; de Almeida, O.P.; Hanemann, J.A.C. Fatal primary diffuse large B-cell lymphoma of the maxillary sinus initially treated as an infectious disease in an elderly patient: A clinicopathologic report. Gerodontology 2018, 35, 59-62. [CrossRef]

25. Gill, D.S.; Cunliffe, D.; Ali, A.; Sternberg, A. Malignant lymphoma of the maxillary sinus masquerading as an odontogenic infection: Report of a case. Dent. Update 2000, 27, 132-134. [CrossRef] [PubMed]

26. Mensch, K.; Szarka, K.; Mensch, H.; Dobai, A.; Magyar, Z.; Pacurar, M.; Vartolomei, A.C.; Manuc, D.; Nagy, C.D. PCR technique assisting the early diagnosis of human papillomavirus a retrospective clinical study. Rev. Chim. 2018, 69, 2781-2787. [CrossRef]

27. Hariram, S.M.; Malkunje, L.R.; Singh, N.; Das, S.; Mehta, G. Ameloblastoma of the anterior mandible. Natl. J. Maxillofac. Surg. 2014, 5, 47-50. [CrossRef]

28. Brody, A.; Zalatnai, A.; Csomo, K.; Belik, A.; Dobo-Nagy, C. Difficulties in the diagnosis of periapical translucencies and in the classification of cemento-osseous dysplasia. BMC Oral Health 2019, 19, 139. [CrossRef]

29. Kawaguchi, M.; Kato, H.; Tomita, H.; Mizuta, K.; Aoki, M.; Hara, A.; Matsuo, M. Imaging Characteristics of Malignant Sinonasal Tumors. J. Clin. Med. 2017, 6, 116. [CrossRef]

30. MacDonald, D.; Lim, S. Extranodal lymphoma arising within the maxillary alveolus: A systematic review. Oral Radiol. 2018, 34, 113-126. [CrossRef]

31. Adwani, D.; Arora, R.; Bhattacharya, A.; Bhagat, B. Non-Hodgkin's lymphoma of maxillary sinus: An unusual presentation. Ann. Maxillofac. Surg. 2013, 3, 95-97. [CrossRef]

32. Dolan, J.M.; DeGraft-Johnson, A.; McDonald, N.; Ward, B.B.; Phillips, T.J.; Munz, S.M. Maxillary and Mandibular Non-Hodgkin Lymphoma with Concurrent Periapical Endodontic Disease: Diagnosis and Management. J. Endod. 2017, 43, 1744-1749. [CrossRef] [PubMed]

33. Longo, F.; De Maria, G.; Esposito, P.; Califano, L. Primary non-Hodgkin's lymphoma of the mandible. Report of a case. Int. J. Oral Maxillofac. Surg. 2004, 33, 801-803. [CrossRef] [PubMed]

34. Pereira, D.L.; Fernandes, D.T.; Santos-Silva, A.R.; Vargas, P.A.; de Almeida, O.P.; Lopes, M.A. Intraosseous Non-Hodgkin Lymphoma Mimicking a Periapical Lesion. J. Endod. 2015, 41, 1738-1742. [CrossRef] [PubMed] 